\title{
Virulence in Oat Crown Rust (Puccinia coronata f. sp. avenae) in the United States from 2006 through 2009
}

\author{
M. L. Carson, United States Department of Agriculture-Agricultural Research Service Cereal Disease Laboratory, St. Paul, MN 55108
}

\begin{abstract}
Carson, M. L. 2011. Virulence in oat crown rust (Puccinia coronata f. sp. avenae) in the United States from 2006 through 2009. Plant Dis. 95:15281534.

The use of race-specific seedling genes for resistance is the primary means of controlling crown rust of oat (Puccinia coronata f. sp. avenae) in the United States. To better utilize those resistance genes, knowledge of the occurrence and frequency of corresponding virulence in the population of $P$. coronata $\mathrm{f}$. sp. avenae in the United States is essential. In total, 571 single-pustule isolates of oat crown rust were collected from cultivated and wild oat (Avena sativa and A. fatua, respectively) in the major oat production areas of the United States from 2006 through 2009. They were tested for virulence on seedlings of 31 differential oat lines in the greenhouse. In all, 201 races were found among the 357 isolates from the spring oat region of the north-central United States, and 140 races were found among 214 isolates from the southern winter oat region. The crown rust populations from the winter and spring oat regions were clearly differentiated from one another, differing in the frequency of virulence for 24 of the 31 differentials. Some virulence associations previously reported in the U.S. oat crown rust population were also found in both regions in this survey, even

to the $P c$ genes were predominately positive in both regions but both positive and negative associations occurred more frequently in the winter oat region, where sexual reproduction does not occur. Some of the virulence diversity in the oat crown rust population in the United States can be related to the deployment of resistance genes in commercial oat cultivars and virulence associations existing in the oat crown rust population. When data from a previous report covering 2001 through 2005 is combined with data reported in this article, the mean virulence of the U.S. populations of crown rust continued to increase from 2001 to 2009. Virulence to Pc38, Pc39, Pc45, Pc48, Pc52, Pc55, $P c 56, P c 57, P c 59, P c 62, P c 63, P c 64, P c 68$, and Pc96 significantly increased in one or both regions during this time period. No significant declines in virulence frequency were found in either region. Genes for crown rust resistance derived from A. sterilis appear to be as rapidly defeated as has happened to $P c$ genes from $A$. sativa. There is an urgent need to find additional sources of effective resistance to $P$. coronata $\mathrm{f}$. sp. avenae and introgress it into adapted oat cultivars.
\end{abstract} when the dataset was clone corrected. Associations between virulence
Crown rust (Puccinia coronata f. sp. avenae P. Syd. \& Syd.) is the most important fungal disease of cultivated oat in the world (20). It can occur wherever oat is grown and is favored by periods of leaf moisture (rainfall or dews) and moderate $\left(21\right.$ to $\left.25^{\circ} \mathrm{C}\right)$ temperatures. From 1981 through 2010, almost 120 million bushels of oat (approximately $1.7 \%$ of the crop) was lost to crown rust in the United States (David Long, personal communication). Losses in individual states ranged up to 20\% (Minnesota in 1991 and Louisiana in 1997). Genetic resistance is the preferred method of controlling losses to crown rust of oat. Cultivars having race-specific, seedling genes ( $P c$ genes), used either singly or in combinations, have been the primary means of control. The effective lifespan of a newly released resistant cultivar has often been 5 years or less because the frequency of virulent races of $P$. coronata rises in response to the deployment of resistant varieties. The diversity of virulence in populations of $P$. coronata $\mathrm{f}$. $\mathrm{sp}$. avenae in the United States is very high because, unlike other cereal rusts, $P$. coronata regularly undergoes sexual recombination in much of the northcentral region. The alternate (pycnial or aecial) host, common buckthorn (Rhamnus carthartica L.), is an invasive woody shrub or small tree that is widely distributed in the understory of woods and shelterbelts in the region.

The objectives of this study were to characterize and contrast the virulence of the oat crown rust population in the winter- and spring-oat-growing regions of the United States from 2006 through

Corresponding author: M. L. Carson, E-mail: mcarson@umn.edu

Accepted for publication 29 June 2011.

doi:10.1094/PDIS-09-10-0639

This article is in the public domain and not copyrightable. It may be freely reprinted with customary crediting of the source. The American Phytopathological Society, 2011.
2009, determine the relative effectiveness of described $P c$ genes used in oat improvement programs against the U.S. crown rust population, and determine trends in virulence over time.

\section{Materials and Methods}

Samples of crown-rust-infected leaves were collected from commercial oat fields and oat research nurseries in annual surveys of cereal rusts in the United States conducted by the United States Department of Agriculture Cereal Disease Laboratory personnel. Survey trips of the major small-grain-producing regions of the central and eastern United States typically begin in early April in southern Texas and continue until mid- to late July in North Dakota and northern Minnesota. In addition to collections made on survey trips, samples are routinely received from collaborators throughout the United States, including G. Bergstrom (New York), R. Harrington (Texas), S. Harrison (Louisiana), K. Burch (Alabama), L. Hall (South Dakota), M. McMullen (North Dakota), J. Mochon (Wisconsin), F. Kolb (Illinois), R. Barnett (Florida), and D. Stuthman (Minnesota and Nebraska). In total, 571 single-pustule isolates were derived from samples collected over the 4-year period of the survey.

Urediniospores were collected from the samples with a cyclone spore collector and inoculated onto 7- to 9-day-old seedlings of either 'Marvellous' or 'Starter' oat. Urediniospores were suspended in light mineral oil (Soltrol 70; ConocoPhillips Inc., Houston, TX) and sprayed onto plants. The mineral oil was allowed to evaporate for approximately $30 \mathrm{~min}$ and the plants were placed overnight into a dew chamber at $18^{\circ} \mathrm{C}$. The inoculated seedlings were returned to the greenhouse and, when uredinia appeared, the plants were trimmed to a single uredinium to represent each sample. Seedlings with single uredinia were placed in a dew chamber for 2 to $3 \mathrm{~h}$ to germinate any urediniospores on the leaf surface and then dried to kill any germinated urediniospores. The plants with single uredinia were then placed into isolation cells in the greenhouse to allow the single uredinia to sporulate further. Urediniospores were collected from those single pustules and inoculated as described above onto 
seedlings of either Marvellous or Starter in isolation cells to increase the single-uredinia-derived cultures. Single uredinial cultures were desiccated at $20 \%$ relative humidity and stored in gelatin capsules at $4^{\circ} \mathrm{C}$ (if used within 2 weeks) or at $-50^{\circ} \mathrm{C}$ in gelatin capsules in plastic cryovials (if not used within 2 weeks of collection). Cultures were heat shocked for $10 \mathrm{~min}$ at $40^{\circ} \mathrm{C}$ before being inoculated onto differential lines. Each single uredinial isolate was tested on a set of 31 differential lines of oat as well as the susceptible control cultivar, Starter. The differential lines are near-isogenic lines developed at either Iowa State University $(P c 14, P c 36, P c 51$, $P c 52, P c 53, P c 70$, and $P c 71)$ or AAFC Cereal Research Centre, Winnipeg, Canada (Pc35, Pc38, Pc39, Pc40, Pc45, Pc46, Pc48, Pc50, Pc54, Pc55, Pc56, Pc62, Pc63, Pc64, Pc67, Pc68, Pc91, $P c 94$, and $P c 96) . P c 58, P c 59, P c 60$, and $P c 61$ were represented by 'TAM-O-301', 'TAM-O-312', 'Coker227', and 'Coker234', respectively (21). A detailed genetic mapping study found that $P c 58$ resistance in TAM-O-301 is actually conditioned by three linked loci (9). Pcl4 was derived from Avena sativa 'Ascencao', Pc91 from A. magna CI8330 (19), Pc94 from A. strigosa RL1697 (1), and $P c 96$ from A. sativa MG85039 (4). All other $P c$ genes in the set of differentials were originally derived from collections of animated oat, A. sterilis L., from the Mediterranean region. Differential lines were grown in vermiculite in $7-\mathrm{cm}^{2}$ pots with 10 to 20 seeds of each of four differential lines planted in each corner of the pot. Seven days after planting, primary leaves of seedlings in each set of differential lines were inoculated with a mineral oil suspension of fresh urediniospores as described previously. Inoculated plants were placed in a dew chamber overnight and moved to a greenhouse bench. Crown rust reactions were measured 12 to 14 days after inoculation. A crown rust reaction of moderately large to large pustules ( $>1 \mathrm{~mm}$ in diameter) with little or no chlorosis was scored as susceptible; those with moderately large to large pustules surrounded with extensive chlorosis were scored as moderately susceptible; those with small pustules $(<0.5 \mathrm{~mm}$ in diameter) surrounded with extensive chlorosis were scored as moderately resistant; those with chlorotic or necrotic flecks were scored as resistant; and those with no visible symptoms were scored as highly resistant (10). For purposes of virulence analysis, isolates produc- ing susceptible or moderately susceptible reactions were considered virulent; all other reactions were considered avirulent.

The virulence data from isolates obtained from the spring oat region (Minnesota, North and South Dakota, Wisconsin, Iowa, Illinois, Kansas, Nebraska, and New York) were pooled for comparison with isolates from the winter oat region (Texas, Oklahoma, Louisiana, Alabama, Florida, Georgia, Mississippi, and North Carolina). Races were determined according to the nomenclature of Chong et al. (6) and their frequency calculated within and between each region. Virulence data were also analyzed using Genepop web-based software (School of Biomedical Sciences, Curtin University of Technology, Bentley, Australia). The frequencies of virulence to each of the 31 differentials in each region were compared using Fisher's exact test (7). Virulence associations within each region were computed on a clone-corrected dataset and tested using Fisher's exact test. Isolates were considered the same clone if they were the same race based on the nomenclature system of Chong et al. (6). The virulence of isolates from commercial oat fields was compared with isolates from oat-breeding nurseries or field plots within each region. Data from a previous study (2) covering 2001 through 2005 were combined with the 2006-to-2009 data to determine whether virulence frequencies had changed over time. Frequencies of virulence within each region and year to each of the 31 differentials were regressed on years to determine whether significant changes were occurring during the 2001-to-2009 time period. Also, the mean virulence of isolates (number of 31 differentials an isolate was virulent upon) was regressed on year of collection, both within each region and with data from both regions combined.

\section{Results}

Races in the United States. In total, 140 races were found among the 214 single-uredinial isolates collected in the winter oat region of the United States (Fig. 1). Seven isolates were given an incomplete race designation and were not included in Figure 1, because disease reactions on one of the 16 race differentials (Pc59) were missing due to poor growth of the differential. Of these 140 races, $109(77.9 \%)$ were represented by a single isolate, 20 $(14.3 \%)$ by 2 isolates, 10 isolates $(7.1 \%)$ were represented by 3 to

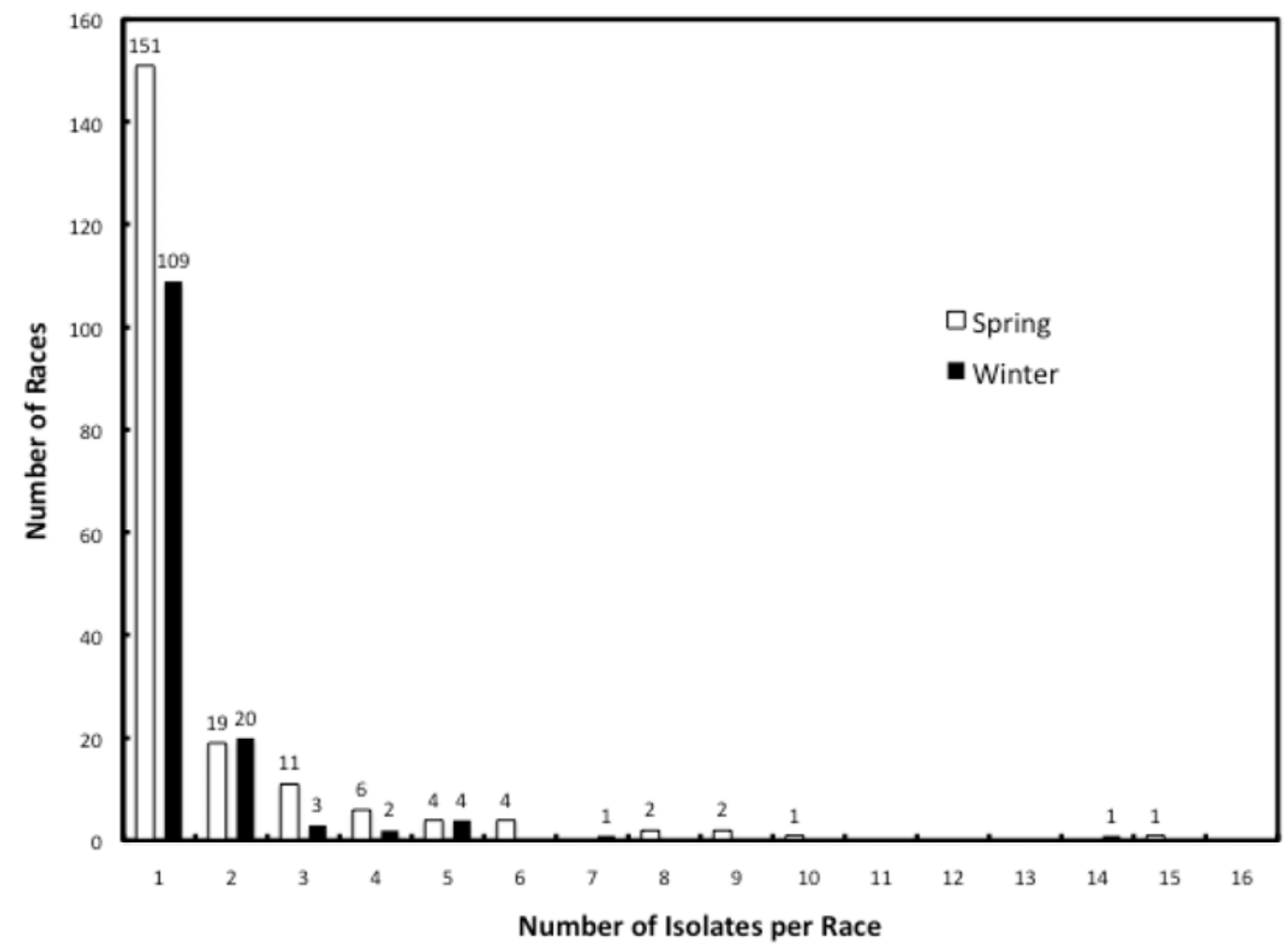

Fig. 1. Frequency distribution of the number of races of Puccinia coronata f. sp. avenae in surveys in the spring and winter oat regions of the United States from 2006 through 2009. 
7 isolates each, and only one race (LQMK) was represented by more than 10 isolates. Five of the six most common races found in the winter oat region, LQMK, NQMG, LBLB, LBLC, and LGMB, all share virulence to $P c 40$ and $P c 51$. The other common race in the winter oat region, GBBB, is only virulent on $P c 45$.

Within the spring oat region, 201 races were found among 357 single-uredinial isolates. Eight isolates from the spring oat region received an incomplete race designation for reasons described above and were omitted from Figure 1. Of these races, 151 $(75.1 \%)$ were represented by a single isolate (Fig. 1). Nineteen races $(9.5 \%)$ were represented by only two isolates. The most common race from the spring oat region was NSRG, represented by 15 isolates. Of the 14 most frequently found races, 13 (NSRG, LQMK, LQLK, NQMG, LTRG, JQMG, DSRG, GQMG, NQLG, DQBG, DQMG, DSQG, and LSRG) were virulent on $P c 38, P c 39$, and $P c 56$.

Combined across both regions, 316 races were found from 2006 through 2009 . Of these, only 27 races were found in both regions. Of the 22 most frequent races, 14 were found exclusively in one region or the other. Only two races, LQMK and NQMG, were found at roughly equal frequency in both oat production regions.

Population differentiation. The oat crown rust population in the winter oat region was clearly differentiated (based on virulence frequencies) from the spring oat regional population, although there was no virulence unique to either region. Virulence to $P c 14$, Pc35, Pc40, Pc54, Pc58, Pc60, Pc61, Pc64, Pc67, and Pc96 was significantly higher in the winter oat region in 2006 to 2009; virulence to Pc36, Pc38, Pc39, Pc46, Pc48, Pc50, Pc51, Pc52, Pc53, $P c 55, P c 56, P c 63, P c 71$, and $P c 94$ was significantly higher in the spring oat region (Fig. 2). Within each region, there was no significant differentiation between isolates from commercial oat fields and those from-breeding nurseries or research plots (data not shown).

Changes in virulence frequency. The virulence of isolates (number of the 31 differentials they were virulent on) collected from 2006 to 2009 ranged from 1 to 25 . During 2001 to 2009, the mean virulence in both the spring and winter oat regions significantly increased from 10.73 to 15.53 and from 10.51 to 14.06 , respectively (Figs. 3 and 4). This increase in the mean virulence of isolates appears to be due to increased virulence to a broad array of $P c$ genes and not to a select few, because there was a positive increase in virulence to 25 and 26 of the specific differentials in the winter and spring oat production regions, respectively (Table 1). In no case were any of the observed decreases in virulence to a specific differential statistically significant. However, virulence to Pc46, Pc57, Pc59, and Pc68 significantly increased in both the winter and spring oat regions. Additionally, virulence to Pc62, $P c 64$, and Pc96 significantly increased in the winter oat region during this time period. In the spring oat region, virulence to $P c 38$, Pc39, Pc45, Pc48, Pc51, Pc52, Pc55, Pc56, and Pc63 also significantly increased from 2001 to 2009.

Virulence associations. In the winter oat region, 152 (33.7\%) of 465 possible virulence associations were significant (Table 2). Of these associations, $26(5.6 \%)$ were negative. In the spring oat region, $107(23 \%)$ of virulence associations were significant, with 4 $(0.8 \%)$ being negative. Forty-seven virulence associations were common to both regions, with all but one, $P c 40$ and $P c 45$, being positive. A single virulence association, $P c 58$ and $P c 71$, was significant but of opposite direction in each region.

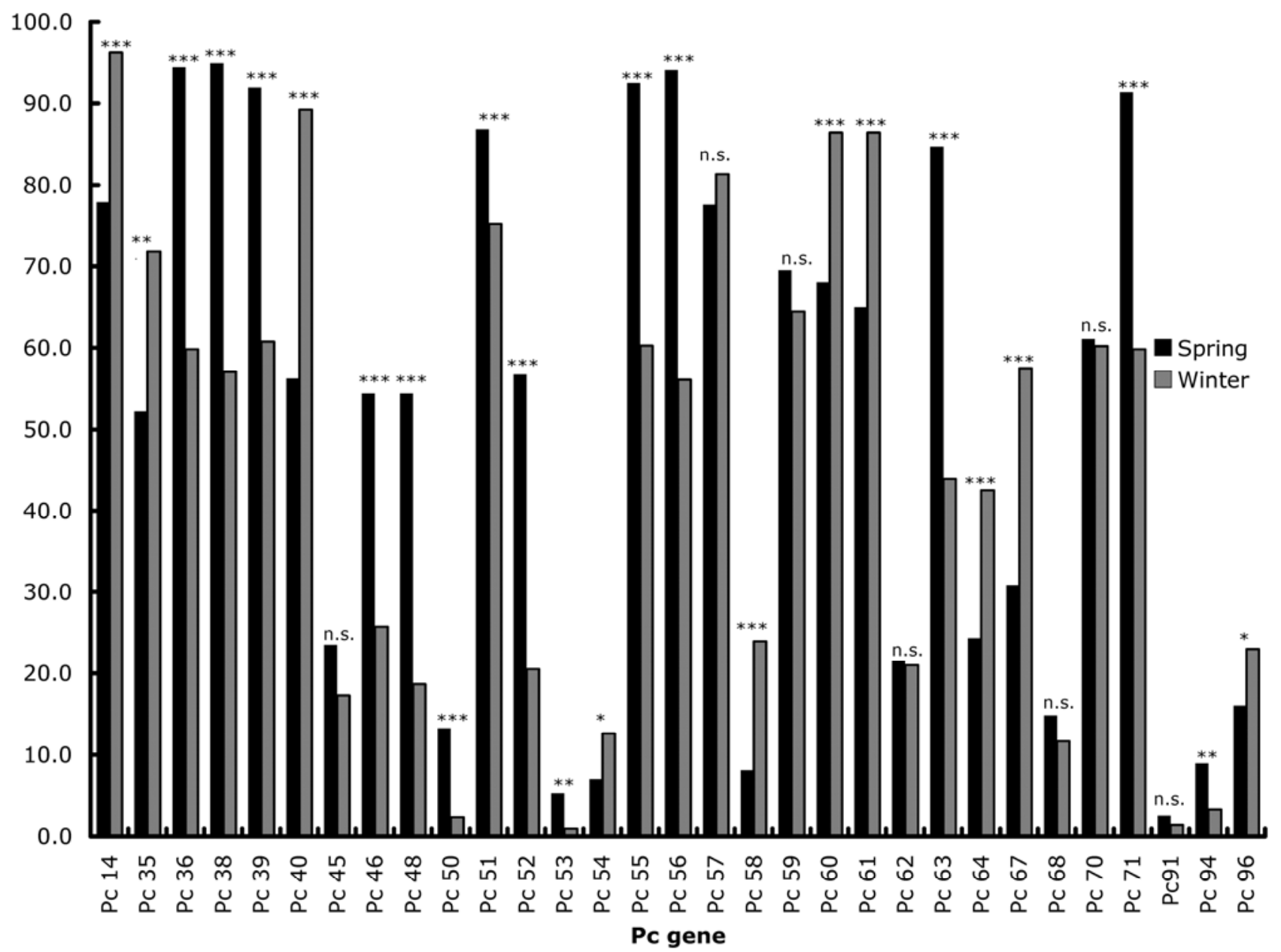

Fig. 2. Frequency of virulence to 31 single Pc gene differential varieties in the population of Puccinia coronata f. sp. avenae surveyed from 2006 through 2009 in the spring and winter oat regions of the United States; ${ }^{*},{ }^{* *}$, and ${ }^{* * *}$ indicate that the frequency of virulence between the two regions is significant at the $0.05,0.01$, and 0.001 levels of probability based on Fisher's exact test. 
Virulence associations observed in this survey were somewhat consistent with those reported previously $(2,12,14)$, with some exceptions. Eighty-nine (57.8\%) virulence associations found previously in the U.S. winter oat region (2) were also found in this survey. In the spring oat region, 45 (46.4\%) were found to be similar to that found in the 2001-to-2005 survey. Four of the eight "persistent" positive virulence associations reported by Leonard (Pc38/Pc63, Pc39/Pc70, Pc36/Pc56, and Pc60/Pc61) in the socalled virulence groups 38 and 61 of Leonard (12), and also found by Carson (2), were found in both regions, and the remaining four (Pc38/Pc39, Pc38/Pc70, Pc39/Pc70, and Pc63/Pc70) were found only in the winter oat region, in this study. Within virulence groups 58 and 45 of Leonard (12), four of the seven persistent virulence associations (Pc14/Pc40, Pc46/Pc57, Pc48/Pc52, and Pc62/Pc64) were found in both regions, two $(P c 35 / P c 70$ and $P c 35 / P c 59)$ were found only in the spring oat region, and one (Pc45/Pc54) was not found in either region.

\section{Discussion}

The oat crown rust population in the United States is highly diverse, regardless of the region of origin of isolates. More than $75 \%$ of races found in either the spring or winter oat region consisted of a single isolate collected over the 4 years of the survey. As was found in a previous survey (2), the two regions had relatively few races in common, reflecting the differentiation between the two populations. This differentiation between regions was also re-

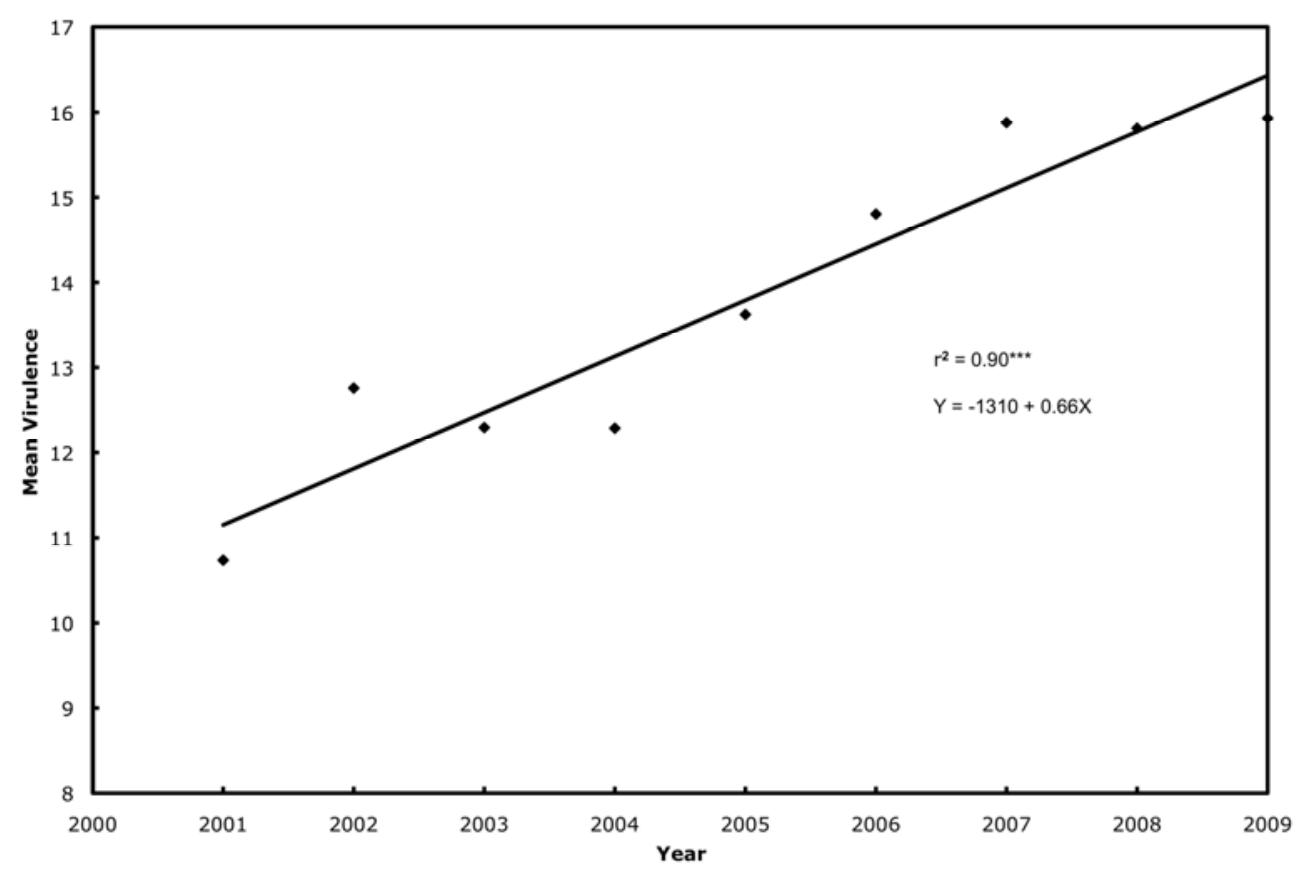

Fig. 3. Regression of the year of collection on the mean virulence of Puccinia coronata f. sp. avenae (mean number of 31 differential varieties isolates were virulent on) from the spring oat region of the United States, from 2001 through 2009; *** indicates that the slope of the regression is significantly different from zero at the 0.001 level of probability.

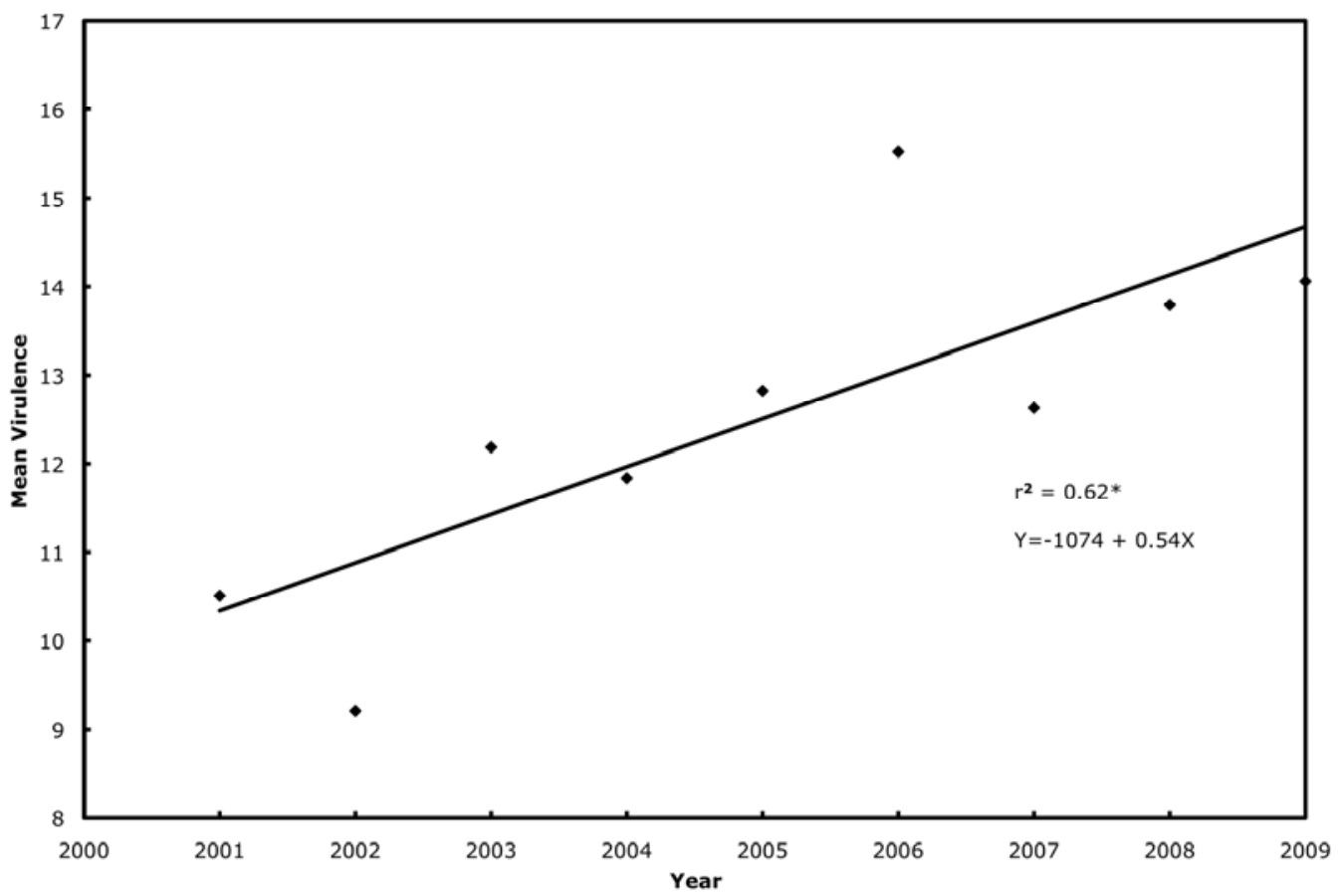

Fig. 4. Regression of the year of collection on the mean virulence of Puccinia coronata f. sp. avenae (mean number of 31 differential varieties isolates were virulent on) from the winter oat region of the United States, from 2001 through 2009; " indicates that the slope of the regression is significantly different from zero at the 0.05 level of probability. 
flected in the significant difference in the frequency but not the occurrence of virulence to 24 of the 31 differential varieties. The most frequent race, LQMK, was found 23 times, predominately in the winter oat region, but was also isolated in the northern spring oat region. Five of the seven most frequent races (isolated at least five times) found in common between the two regions were predominately found in the spring oat region, with a few isolates found in the winter oat region. This is somewhat in contrast with what was observed in a previous survey, where the frequency of races common to the two regions was higher in the winter oat region. This is evidence that, although crown rust populations in the two regions are distinct, the two populations are not completely isolated and there is still significant movement of isolates between regions via the "Puccinia pathway" (20). Some of these regional differences in virulence frequency reflect the use of corresponding resistance genes in the respective regions. Virulence to $P c 38, P c 39$, and $P c 48$ is significantly higher in the spring oat region, where these genes have been used extensively in oat-breeding programs. Similarly, virulence to Pc58, Pc60, and $P c 61$ was higher in the winter oat region, where these genes were widely used in the Texas A\&M and Coker breeding programs. The increase in virulence to Pc48 from 2001 through 2005 in the spring oat region is likely due to its deployment in numerous spring oat cultivars and is now approaching $60 \%$. Virulence to $P c 48$ increased rapidly in the prairie provinces of Canada when it was deployed in 'Triple Crown' (5). Similarly, the increase in virulence to $P c 59$ in the winter oat region is likely due its use in the popular cultivar Tam-O-312. Tam-O-312 has also been widely used in some spring oat programs but no cultivar with Pc59 has been released in the spring oat region. The significant decrease in virulence to Pc53 in the winter oat region is not easily explained, because this gene has not been used in any cultivars other than some component lines of the Iowa multilines. Virulence to Pc53 has never been common in the United States $(2,11)$ but was totally absent from the winter oat region in the last 3 years of the survey.
Virulence to Pc68 is increasing in the U.S. crown rust population, reaching $30 \%$ in the spring oat region in 2008. In the prairie provinces of Canada, virulence to Pc68 is now over $80 \%$ in commercial oat fields (5). Pc68 has been widely used in the prairie provinces of Canada in 'AC Assiniboia', 'Ronald', 'AC Medallion', and other oat cultivars, and is being used in several U.S. oat-breeding programs as well. In previous surveys in the United States and Canada, virulence to $P c 45$ was absent or at a very low frequency $(2,11)$, suggesting that it might be useful in U.S. oat-breeding programs. However in this study, virulence to Pc45 was significantly increasing in the spring oat region, reaching a frequency of $37 \%$ in 2009. This increase paralleled an increase in virulence to IAB605X, a genetically uncharacterized isoline developed by Iowa State University with resistance from A. sterilis that has been used in the popular 'Kame' and 'Morton' oat. Virulence to Pc45 and IAB605X was highly correlated $(P<0.001)$ among isolates in this survey (data not shown). Virulence to Pc45 is high in California (11), Mexico (15), Israel (13), South America (16), and South Africa (22), indicating little apparent fitness cost to carrying this unnecessary virulence in the pathogen population, because Pc45 is not known to be used in any oat cultivars in these areas. The frequency of virulence to Pc53 in the United States remains low, suggesting that it might be a useful gene in oat breeding. However, virulence is common in Uruguay and Brazil (16), indicating that its effectiveness might not last long if used in U.S. oat cultivars. Virulence to $P c 91$, a resistance gene from 'Amagalon' (A. magna $\times A$. longiglumis; 19) that is in the widely grown 'HiFi' from North Dakota State University, has remained at a low level in both the spring and winter oat regions during the survey period, an indication that $P c 91$ may provide more durable resistance than other $P c$ genes. Virulence to Pc94, a resistance gene from A. strigosa (1) that is in the Canadian 'Leggett', increased, although not significantly, during the survey period to over $10 \%$ in the spring oat region. Virulence was also found in both oat-growing regions to Pc96, another new gene from A. sativa that is being used in the Winnipeg oat-breeding program (4). Given that virulence to Pc96

Table 1. Slopes of the regression of virulence frequencies in Puccinia coronata f. sp. avenae on 31 oat differential lines over years (2001 to 2009) in the winter- and spring-oat-growing regions of the United States ${ }^{\mathrm{a}}$

\begin{tabular}{|c|c|c|}
\hline Oat differential and source of resistance & Winter region & Spring region \\
\hline Pc14 (Avena sativa 'Ascencao') & 0.0011 & -0.0188 \\
\hline Pc35 (A. sterilis D-137) & -0.0270 & -0.0073 \\
\hline Pc36 (A. sterilis CI 8081) & 0.0133 & 0.0267 \\
\hline Pc38 (A. sterilis CW491-4) & 0.0261 & $0.0368 *$ \\
\hline Pc39 (A. sterilis $\mathrm{F}-366)$ & 0.0493 & $0.0275^{*}$ \\
\hline Pc40 (A. sterilis $\mathrm{F}-83)$ & -0.0054 & -0.0295 \\
\hline Pc45 (A. sterilis $\mathrm{F}-169)$ & 0.0097 & $0.0430 * *$ \\
\hline Pc46 (A. sterilis $\mathrm{F}-290)$ & $0.0259 *$ & $0.0479 *$ \\
\hline Pc48 (A. sterilis $\mathrm{F}-158)$ & 0.0092 & $0.0499 * *$ \\
\hline Pc50 (A. sterilis $\mathrm{CW}-486)$ & -0.0018 & 0.0082 \\
\hline Pc51 (A. sterilis Wahl number 8) & 0.0255 & $0.0580 *$ \\
\hline Pc52 (A. sterilis Wahl number 2 ) & 0.0142 & $0.0496 * *$ \\
\hline Pc53 (A. sterilis 6-112-1-15) & -0.0074 & 0.0069 \\
\hline Pc54 (A. sterilis CAV 1832) & -0.0014 & -0.0068 \\
\hline Pc55 (A. sterilis CAV 4963) & 0.0491 & $0.0303 *$ \\
\hline Pc56 (A. sterilis CAV 1964) & 0.0146 & $0.0341 *$ \\
\hline Pc57 (A. sterilis CI 8295) & $0.0785 * *$ & $0.0713^{* *}$ \\
\hline Pc58 (A. sterilis PI 295919) & -0.0117 & 0.0025 \\
\hline Pc59 (A. sterilis PI 296244) & $0.0296 *$ & $0.0338 * * *$ \\
\hline Pc60 (A. sterilis PI 287211) & 0.0034 & 0.0327 \\
\hline Pc61 (A. sterilis PI 287211) & 0.0070 & 0.0374 \\
\hline Pc62 (A. sterilis CAV 4274) & $0.0388 * *$ & 0.0210 \\
\hline Pc63 (A. sterilis CAV 4540) & 0.0393 & $0.0480 *$ \\
\hline Pc64 (A. sterilis CAV 4248) & $0.0462 *$ & 0.0182 \\
\hline Pc67 (A. sterilis CAV 4656) & 0.0102 & 0.0152 \\
\hline Pc68 (A. sterilis CAV 4904) & $0.0223 *$ & $0.0265 *$ \\
\hline Pc70 (A. sterilis PI318282) & 0.0019 & -0.0129 \\
\hline Pc71 (A. sterilis IA B437) & 0.0476 & 0.0225 \\
\hline Pc91 (A. magna CI 8330) & 0.0009 & 0.0003 \\
\hline Pc94 (A. strigosa RL1697) & 0.0193 & 0.0288 \\
\hline Pc96 (A. sativa MG85039) & $0.1094 * *$ & 0.0455 \\
\hline
\end{tabular}

a Asterisks: *, **, and $* * *$ indicate that the slope is significantly different from zero at the $0.05,0.01$, and 0.001 levels of probability, respectively. 
increased significantly in the winter oat region from 2005 to 2009 (reaching over $40 \%$ in 2009), its useful lifespan in any cultivar is probably very limited.

Virulence associations, particularly positive ones, were common in the U.S. crown rust population in this study and previous reports $(2,12,14)$. The higher frequency of associations among virulence in the winter oat region compared with the spring oat region may be due, in part, to the lack of sexual recombination in the winter oat region because the alternate host buckthorn does not occur there. The presence of many virulence associations in the spring oat region, where sexual recombination on buckthorn occurs regularly, may be attributed to selection favoring genotypes with paired virulences (12). Even though some of the virulence associations previously reported were also found in this study, there were some exceptions, as noted above. These inconsistencies may be the result of the aggregation of isolates over multiple years and over wide geographic areas in this study, resulting in apparent linkage disequilibria (or lack thereof) if frequencies of virulence fluctuated between years or between areas lumped together in the analysis (12). Clone correcting the dataset in this survey did slightly reduce the percentage of virulence associations that were significant compared with the previous survey (2): 23 versus 26 and 39 versus $40 \%$ for the spring and winter oat regions, respectively.

The continued increase in the mean virulence of the U.S. oat crown rust population in this and previous reports $(2,11)$ does not bode well for the success of exploiting race-specific seedling genes, either singly or in combination, for crown rust control in oat. $P c$ genes derived from A. sterilis appear to be suffering the same fate as those derived from A. sativa, where the frequency of corresponding virulence in the pathogen population is now near fixation (6). Virulence frequencies to some of the more commonly used $P c$ genes from A. sterilis are over $70 \%$ in one or both oatgrowing regions of the United States. Furthermore, there is no apparent fitness cost for isolates carrying virulence to many $P c$ genes (2,11-14). Also, there does not appear to be any strong, consistent negative associations between virulences that could possibly be exploited by deploying cultivars with the corresponding combination of $P c$ genes $(2,12,14)$.

The development of durable resistance to crown rust through the use of seedling $P c$ genes remains elusive. There is nothing from previous experience of using $P c$ genes to indicate that future attempts will be any more durable. Oat improvement programs should consider shifting their efforts toward race nonspecific, partial forms of crown rust resistance. This type of resistance has long been recognized in cultivated hexaploid oat $(8,10,17)$ but it has received little attention in most oat improvement programs in the United States. Difficulties in selecting for this type of resistance in the presence of seedling genes that are effective against most of the crown rust population, its relatively low heritability, its association with late maturity, and the poor agronomic performance of many of the sources of partial resistance may have hindered its use. The highly effective, partial resistance found in the experimental oat line MN841801 (10) is controlled by either two additive genes (3) or seven (four major and three minor) quantitative trait loci (QTL; 18). The development of molecular markers suitable for marker-assisted selection of QTL for partial resistance in oat may remove some of the barriers to its use in oat improvement.

Table 2. Associations between virulence to 31 crown rust resistance $(\mathrm{Pc})$ genes in the oat crown rust populations in spring (above the diagonal) and in winter (below the diagonal) oat production areas of the United States from 2006 through $2009^{\text {a }}$

\begin{tabular}{|c|c|c|c|c|c|c|c|c|c|c|c|c|c|c|c|c|c|c|c|c|c|c|c|c|c|c|c|c|c|c|c|}
\hline \multicolumn{32}{|c|}{ Pc gene } \\
\hline & 14 & 35 & 36 & 38 & 39 & 40 & 45 & 46 & 48 & 50 & 51 & 52 & 53 & 54 & 55 & 56 & 57 & 58 & 59 & 60 & 61 & 62 & 63 & 64 & 67 & 68 & 70 & 71 & 91 & 94 & 96 \\
\hline 14 & -- & & & & & $* * *$ & & & & & & & & & & & & & & **** & $*$ & $* * *$ & & ** & *** & & & & & & **** \\
\hline 35 & $* *$ & -- & & & * & & & & & & & & *** & & * & & & *** & $* *$ & & & & & & & & $* * *$ & & & \# & \\
\hline 36 & & & -- & * & & & & & *** & & ** & *** & & & & *** & & & & & * & * & & & & & & & & & \\
\hline 38 & & & $* * *$ & -- & & & & & & & & & & & & & & & & & & & $* * *$ & & & & & & & & \\
\hline 39 & & & $*$ & $* * *$ & -- & & & & & * & & & & & $* * *$ & & & & & ${ }^{* * *}$ & * & & & & & $*$ & $* * *$ & $* * *$ & & & \\
\hline 40 & $* * *$ & $* * *$ & & & & -- & \#\# & & & & & & & & & & & & & $* *$ & ** & * & & *** & **** & & & & & & $* *$ \\
\hline 45 & & \#\# & & & & \#\# & -- & & & & & & **** & & $*$ & & & & $* * *$ & & & & $* * *$ & & & $*$ & & & & & \\
\hline 46 & & & ** & $* * *$ & **** & & & -- & & & & & & & & & $* * *$ & & & & & & & & & & & & & & \\
\hline 48 & & & * & *** & **** & & & & -- & & **** & *** & & $*$ & & *** & & & $*$ & & & & & & & ** & & & & *** & \\
\hline 50 & & & & & & & & & & -- & & & & & & & & & & & & & & & & * & & & & & \\
\hline 51 & & & & & * & * & & & $*$ & & -- & $* * *$ & & & & $* *$ & & & & & & $* * *$ & & * & $* *$ & ** & & & & & $* *$ \\
\hline 52 & & & $* *$ & **** & $* * *$ & & & & $* * *$ & & $* *$ & -- & & & & $* *$ & & & $* *$ & & & & & & & $*$ & * & & & $* *$ & \\
\hline 53 & & & & & & & * & & & & & & -- & & & & & & & & & & & & & $*$ & & & & & \\
\hline 54 & & & & & & & & & & & & & & -- & & & & & & * & *** & & & & & & & & & & \\
\hline 55 & & & $*$ & $* * *$ & *** & & & **** & **** & & * & $* *$ & & & -- & & & & & **** & $*$ & & * & & & ** & $* * *$ & $* * *$ & & \# & * \\
\hline 56 & & & ${ }^{* * *}$ & $* * *$ & & & & $* *$ & * & & & $* *$ & & & & -- & $*$ & & & ${ }^{* *}$ & ${ }^{* *}$ & $* *$ & & & & & & & & & \\
\hline 57 & & * & & **** & * & & & *** & & & $* *$ & & & & $* *$ & & -- & & $*$ & ** & **** & & & & & $\#$ & & & & & \\
\hline 58 & & $* * *$ & & & \#\#\# & & & \#\# & & & & & & \# & \#\#\# & & & -- & * & $* * *$ & & & & & & & $* *$ & {$\left[{ }^{*}\right]$} & & & \\
\hline 59 & & & ${ }^{* * * *}$ & $*$ & $*$ & & & ${ }^{*}$ & & & & ** & & & $*$ & *** & & & -- & & * & & & & & & ${ }^{*}$ & & & & \\
\hline 60 & & & & & & & & & & & & & & & & & *** & & & -- & $* * *$ & **** & & * & & & & $*$ & & & *** \\
\hline 61 & & **** & & & & $* *$ & $\#$ & & & & $* *$ & & & & & & $* * *$ & *** & * & *** & -- & ** & & ** & & & & & & & $* *$ \\
\hline 62 & & & * & $*$ & **** & & & & & & **** & & & & **** & ** & & & & $*$ & & -- & & *** & **** & & & & & & $* * *$ \\
\hline 63 & & & *** & $* * *$ & $* * *$ & & & $* * *$ & $* *$ & & $*$ & $* *$ & & & $* * *$ & $* * *$ & **** & $\# \#$ & $* * *$ & . & & $* * *$ & -- & & & & & $* *$ & & & \\
\hline 64 & * & & & & \#\# & & & \#\# & $\#$ & & & & & \# & \#\# & & & $*$ & & $* *$ & ${ }^{* * *}$ & $* * *$ & & -- & $* * *$ & & & & & & $* * *$ \\
\hline 67 & & \#\# & **** & & $\#$ & & & & & & & & & & \# & **** & \# & & & & & & & *** & -- & & & & & & $* * *$ \\
\hline 68 & $*$ & & & $*$ & *** & & & & $* * *$ & & & $* * *$ & & & $* * *$ & & & \#\# & & \# & & & $*$ & & & -- & $*$ & $*$ & & **** & *** \\
\hline 70 & & & & ${ }^{* * *}$ & $* * *$ & & & $* *$ & ** & & & $* * *$ & & & $* * *$ & & & & & & & & **** & \#\# & \# & & -- & $* * *$ & & & \\
\hline 71 & & & $*$ & **** & **** & & & **** & $* * *$ & & *** & **** & & & *** & & *** & [\#\#\#] & *** & & & $* *$ & *** & \#\#\# & \# & $*$ & $* * *$ & -- & & & \\
\hline 91 & & & & & & & & & $*$ & & & $*$ & & & & & & & & & & & & & & & & & -- & & \\
\hline 94 & & & & & & & & & $* *$ & & & & & & & & & & & & & & & & & & \#\#\# & & ** & -- & \\
\hline 96 & & & * & *** & **** & & & & * & & & & & \# & $* * *$ & $*$ & & \#\# & & & & *** & **** & **** & & * & & $* * *$ & & & -- \\
\hline
\end{tabular}

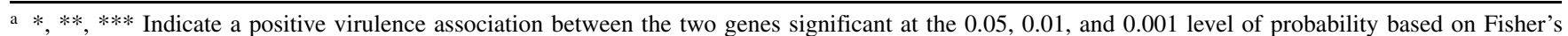
exact test. Highlighted cells indicate a significant association was found in both oat production areas. \#, \#\#, \#\#\# Indicate a negative virulence association between the two genes significant at the $0.05,0.01$, and 0.001 level of probability based on Fisher's exact test. [ ] Indicate virulence association between the two genes was of opposite direction in the two production areas. 


\section{Literature Cited}

1. Aung, T., Chong, J., and Leggett, M. 1996. The transfer of crown rust resistance Pc94 from a wild diploid to cultivated hexaploid oat. Pages 167-171 in: Proc. 9th Int. Eur. Mediterr. Cereal Rusts and Powdery Mildews Conf. Lunteren, The Netherlands. G. H. J. Kema, R. E. Niks, and R. A. Daamen, eds. European and Mediterranean Cereal Rust Foundation, Wageningen, The Netherlands.

2. Carson, M. L. 2008. Virulence frequencies in oat crown rust in the United States from 2001 through 2005. Plant Dis. 92:379-384.

3. Chong, J. 2000. Inheritance of resistance to two Puccinia coronata isolates in a partial resistant oat line MN841801. Acta Phytopathol. Entomol. Hung. 35:37-40.

4. Chong, J., and Brown, P. D. 1996. Genetics of resistance to Puccinia coronata f. sp. avenae in two Avena sativa accessions. Can. J. Plant Pathol. 18:286-292.

5. Chong, J., Gruenke, J., Dueck, R., Mayert, W., and Woods, S. 2008. Virulence of oat crown rust (Puccinia coronata f. sp. avenae) in Canada during 2002-2006. Can. J. Plant Pathol. 30:115-123.

6. Chong, J., Leonard, K. J., and Salmeron, J. J. 2000. A North American system of nomenclature for Puccinia coronata f. sp. avenae. Plant Dis. 84:580585 .

7. Good, P. 2005. Permutation, Parametric, and Bootstrap Tests of Hypotheses, 3rd ed. Springer, New York.

8. Heagle, A. S., and Moore, M. B. 1970. Some effects of moderate adult resistance of oats. Phytopathology 60:461-466.

9. Hoffman, D. L., Chong, J., Jackson, E. W., and Obert, D. E. 2006. Characterization and mapping of a crown rust gene complex (Pc58) in TAM O-301. Crop Sci. 46:2630-2635.

10. Leonard, K. J. 2002. Oat lines with effective adult plant resistance to crown rust. Plant Dis. 86:593-598.

11. Leonard, K. J. 2003. Regional frequencies of virulence in oat crown rust in the United States from 1990 through 2000. Plant Dis. 87:1301-1310.

12. Leonard, K. J. 2007. Persistent virulence associations in sexual populations of Puccinia coronata. Plant Pathol. 56:35-45.

13. Leonard, K. J., Anikster, Y., and Manisterski, J. 2004. Patterns of virulence in natural populations of Puccinia coronata on wild oat in Israel and in agricultural populations on cultivated oat in the United States. Phytopathology 94:505-514.

14. Leonard, K. J., Anikster, Y., and Manisterski, J. 2005. Virulence associations in oat crown rust. Phytopathology 95:53-61.

15. Leonard, K. J., Huerta-Espino, J., and Salmeron, J. J. 2005. Virulence of oat crown rust in Mexico. Plant Dis. 89:941-948.

16. Leonard, K. J., and Martinelli, J. 2005. Virulence of oat crown rust in Brazil and Uruguay. Plant Dis. 89:802-808.

17. Luke, H. H., Chapman, W. H., and Barnett, R. D. 1972. Horizontal resistance of Red Rustproof oats to crown rust. Phytopathology 62:414-417.

18. Portyanko, V. A., Chen, G., Rines, H. W., Phillips, R. L., Leonard, K. J., Ochocki, G. E., and Stuthman, D. D. 2001. Quantitative trait loci for partial resistance to crown rust, Puccinia coronata, in cultivated oat, Avena sativa L. Theor. Appl. Genet. 111:313-324.

19. Rooney, W. L., Rines, H. W., and Phillips, R. L. 1994. Identification of RFLP markers linked to crown rust resistance genes $P c 91$ and $P c 92$ in oat. Crop Sci. 39:940-944

20. Simons, M. D. 1985. Crown rust. Pages 131-172 in: The Cereal Rusts: Vol II. Diseases, Distribution, Epidemiology, and Control. A. P. Roelfs and W. R. Bushnell, eds. Academic Press, Orlando, FL.

21. Simons, M. D., Martens, J. W., McKenzie, R. I. H., Nishiyama, L., Sadanaga, K., Sebesta. J., and Thomas, H. 1978. Oats: a Standardized System of Nomenclature for Genes and Chromosomes and Catalog of Genes Governing Characters. U. S. Dep. Agric. Publ. No. 509. (Agricultural Handbook Series).

22. van Niekerk, B. D., Pretorius, Z. A., and Boshoff, W. H. P. 2001. Pathogenic variability of Puccinia coronata f. sp. avenae and $P$. graminis $\mathrm{f}$. sp. avenae on oat in South Africa. Plant Dis. 85:1085-1090. 